\title{
Beneficial Role of Reduced Graphene Oxide for Electron Extraction in Highly Efficient Perovskite Solar Cells
}

\author{
Kyung Taek Cho, ${ }^{[\mathrm{a}]}$ Giulia Grancini, ${ }^{[\mathrm{a}]}$ Yonghui Lee, ${ }^{[\mathrm{a}]}$ Dimitrios Konios, ${ }^{[\mathrm{b}]}$ Sanghyun Paek, ${ }^{[\mathrm{a}]}$ \\ Emmanuel Kymakis, ${ }^{[b]}$ and Mohammad Khaja Nazeeruddin* ${ }^{*[a, c]}$
}

\begin{abstract}
In this work we systematically investigated the role of reduced graphene oxide ( $\mathrm{rGO}$ ) in hybrid perovskite solar cells (PSCs). By mixing $\mathrm{rGO}$ within the mesoporous $\mathrm{TiO}_{2}\left(\mathrm{~m}-\mathrm{TiO}_{2}\right)$ matrix, highly efficient solar cells with power conversion efficiency values up to $19.54 \%$ were realized. In addition, the boosted beneficial role of $\mathrm{rGO}$ with and without Li-treated $\mathrm{m}-\mathrm{TiO}_{2}$ is highlighted, improving transport and injection of photoexcited electrons. This combined system may pave the way for further development and optimization of electron transport and collection in high efficiency PSCs.
\end{abstract}

Since its isolation in 2004, ${ }^{[1]}$ graphene has had a huge impact on applications in optoelectronic and photon energy conversion, owing to its unique electronic, optical, and mechanical properties. ${ }^{[2-5]}$ The development of solution-processable graphene, such as the chemical exfoliation of graphite into graphene oxide, allowed the functionalization and processing of graphene, extending its use in the different layers of solutionprocessable solar cells. ${ }^{[6,7]}$ Among different solar cell technologies, organic-inorganic hybrid perovskite solar cells (PSCs) have been dominating the interest of the scientific research community for their impressive technological development with power conversion efficiency (PCE) values beyond $22 \%$ in a short of six years of research. ${ }^{[8]}$ However, further improvements are necessary to optimize the PSC device operation and stability, and enhance the device performance. From this point, mixed graphene-based derivatives have been proposed to further enhance the device properties. ${ }^{[7]}$ Used in various forms and with different functionalities, either incorporated in mesoscopic or in planar device configuration, ${ }^{[9,10]}$ functionalized re-

[a] K. T. Cho, Dr. G. Grancini, Dr. Y. Lee, Dr. S. Paek, Prof. M. K. Nazeeruddin Group for Molecular Engineering of Functional Materials

Institute of chemical Sciences and Engineering

École Polytechnique Fédérale de Lausanne

Sion $\mathrm{CH}-1951$ (Switzerland)

E-mail:mdkhaja.nazeeruddin@epfl.ch

[b] D. Konios, Prof. E. Kymakis

Center of Materials Technology and Photonics \& Electrical Engineering Department School of Applied Technology

Technological Educational Institute (T.E.I) of Crete Heraklion 71004 Crete (Greece)

[c] Prof. M. K. Nazeeruddin

Center of Excellence for Advanced Materials Research (CEAMR) King Abdulaziz University Jeddah (Saudi Arabia) $\square$ Supporting Information and the ORCID identification number(s) for the
iD author(s) of this article can be found under http://dx.doi.org/10.1002/ cssc. 201601070. duced graphene oxide ( $\mathrm{rGO}$ ) derivatives have been successfully employed for improved charge extraction in the electrontransport material $(\mathrm{ETM})^{[9,11,12]}$ or hole-transport material $(\mathrm{HTM})^{[13]}$ in PSCs. Its ability to effectively reduce the chargerecombination pathways and decrease the leakage currents has been demonstrated, with a similar role as in organic solar cells. ${ }^{[14-16]}$ However, all of the PCEs reported are limited to less than $14 \%$ and the perovskite was not formed as a perfect film, which casts the doubt on the real beneficial role of $\mathrm{rGO}$ on high-efficiency PSCs. In contrast to many applications of carbon-based materials that are usually introduced at the perovskite/ $/ \mathrm{TiO}_{2}$ or perovskite/HTM interfaces, or in substitution of the HTM itself, ${ }^{[17,18]}$ here we propose a systematic study by exploring three different configurations as shown in Figure 1.

We integrated the rGO: 1 ) in the $2,2^{\prime}, 7,7^{\prime}$-tetrakis $\left(N, N^{\prime}\right.$-di- $p$ methoxyphenylamine)-9,9'-spirobifluorene (spiro-OMeTAD) HTM, 2) in the matrix of the active perovskite layer, and 3) within the mesoporous $\mathrm{TiO}_{2}\left(\mathrm{~m}-\mathrm{TiO}_{2}\right)$ ETM. In this study, mesoscopic PSCs are composed of a fluorine doped tin oxide (FTO)-coated glass substrate, a compact $\mathrm{TiO}_{2}$ layer followed by a $\mathrm{m}-\mathrm{TiO}_{2}$ layer, a mixed $\left(\mathrm{FAPbl}_{3}\right)_{0.85}\left(\mathrm{MAPbBr}_{3}\right)_{0.15}(\mathrm{FA}=$ formamidinium, $M A=$ methylammonium) perovskite layer that infiltrates into the $\mathrm{m}-\mathrm{TiO}_{2}$, a spiro-OMeTAD layer, and a Au counter electrode. ${ }^{[19]}$ We investigate the effect of the introduction of the $\mathrm{rGO}$ flakes in each layer comparing the results with control cells without rGO. Furthermore, to better examine the effect of rGO in the ETM, we compared devices with and without treating the $\mathrm{TiO}_{2}$ surface with lithium bistrifluoromethanesulfonimidate (Li-TFSI), which was recently shown to improve the device performance by facilitating the interfacial electron injection. ${ }^{[20]}$ The different device architectures are illustrated in Figure $1 \mathrm{a}-\mathrm{c}$, where $\mathrm{rGO}$ has been included in the $\mathrm{m}-\mathrm{TiO}_{2}$ layer, mixed perovskite layer, and spiro-OMeTAD layer, respectively. Energy level diagrams are inserted in the cartoon in Figure $1 \mathrm{~d}-\mathrm{f}^{[21,22]}$

The characterization of $\mathrm{rGO}$, along with the calculations of the $\mathrm{rGO}$ HOMO/LUMO levels, being approximately -4.96/ $-3.95 \mathrm{eV}$, respectively, are explained in Figures S1 and S2. As the energy level of $\mathrm{rGO}$ is lower than the $\mathrm{TiO}_{2}$ and mixed perovskite, we expect that a photoexcited electron can be extracted through the rGO plates. The cross-sectional scanning electron microscopy (SEM) images of the four studied PSC architectures are provided in Figure S3, showing the similar layered device structure. The current density-voltage $(J-V)$ characteristics of the best devices for each architecture along with the device parameters are shown in Figure 2 and Table 1, respectively. Initially, these devices were fabricated with Li-treated $\mathrm{TiO}_{2}$ layers. Depending on the $\mathrm{rGO}$ mixing layer, the perform- 
a

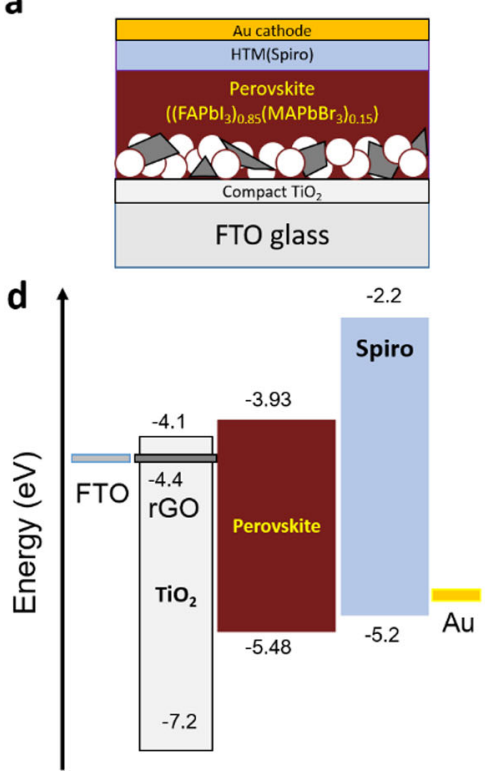

b

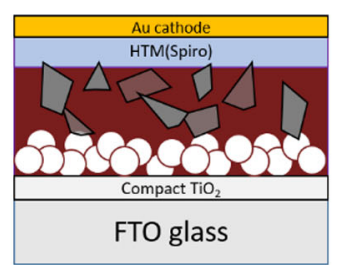

e

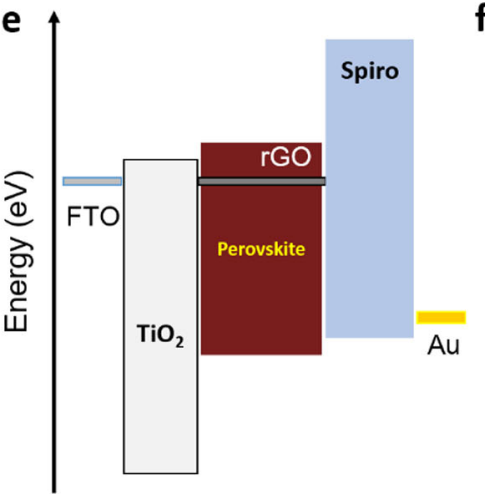

c

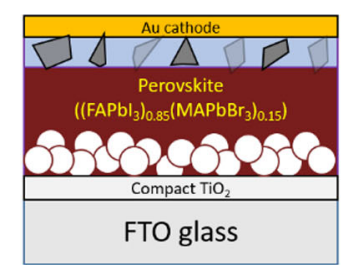

f

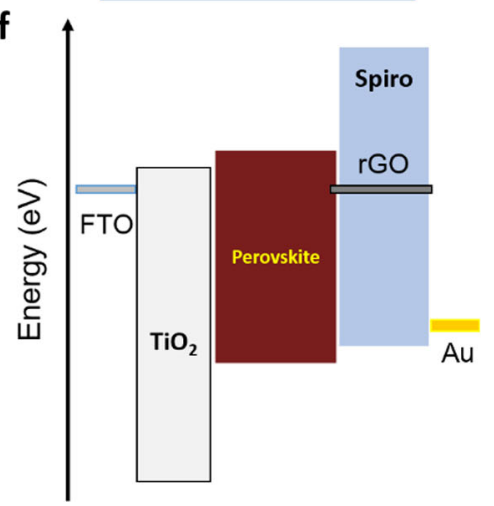

Figure 1. Illustration of the solar cells architectures fabricated with rGO in each layer: (a) $\mathrm{m}-\mathrm{TiO}_{2}+\mathrm{rGO}$, (b) perovskite + rGO, and c) spiro-OMeTAD + rGO. (df) The corresponding energy level diagram of these three devices. These energy levels are based on the individual materials; within the solar cell and under illumination there will be a relative shift.

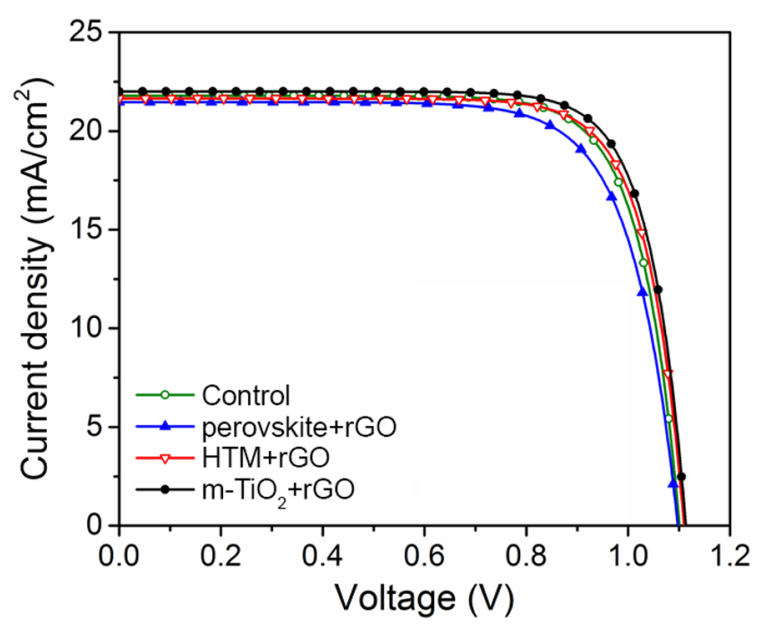

Figure 2. $J-V$ curves of the best performing devices for each architecture described in Figure 1, measured under AM 1.5 G solar irradiation of $100 \mathrm{~mW} \mathrm{~cm}^{-2}$. The solar cell parameters are summarized in Table 1. ances vary dramatically. It is found that the presence of $\mathrm{rGO}$ in the $\mathrm{m}-\mathrm{TiO}_{2}$ layer has a strong positive impact on the device performances. Relative to the control cell (without rGO), which provides a PCE of $18.8 \%$ (see Table 1), incorporation of rGO in the $\mathrm{m}-\mathrm{TiO}_{2}$ layer yields improved device performance with a PCE of $19.5 \%$.

When the $\mathrm{rGO}$ is mixed in the spiro-OMeTAD or perovskite layers (Figure $1 \mathrm{~b}$ and $\mathrm{c}$ ), we observed no significant improvement in the device performance, and similar or lower PCEs were obtained (Table 1). Interestingly, these results are in contrast to what was observed in the literature, where it is indicated that $\mathrm{rGO}$ always plays a positive role for improving the PCE of PSCs. ${ }^{[9-11,23,24]}$ The reduced photovoltaic performance when rGO is mixed either with the perovskite or with the spiroOMeTAD layers can be attributed to a detrimental effect of the rGO in the device structure. This observation comes from the analysis of SEM top-view (Figure 3). In Figure $3 \mathrm{a}$ and $\mathrm{c}$ the topsurface of the neat perovskite and spiro-OMeTAD layers are compared to the ones that include rGO (Figure $3 \mathrm{~b}$ and $\mathrm{d}$, respectively). When $\mathrm{rGO}$ is incorporated either within the perovskite or spiro-OMeTAD layer, the film is no longer homogeneous; incorporation of $\mathrm{rGO}$ is responsible for the formation of nanoflakes that disrupt the crystal quality. This leads to additional shunt pathways that negatively affect the perovskite device performances. Direct pathways between the perovskite and the top $\mathrm{Au}$ electrode or the bottom $\mathrm{TiO}_{2}$ and spiro-OMeTAD can be easily generated by the rGO flakes, increasing the possibility of charge recombination and leading to the reduced device performances observed. Note that this effect is amplified when the $\mathrm{rGO}$ is mixed within the perovskite, creating unwanted electronleakage flow toward spiro-OMeTAD (Figure S4). On 

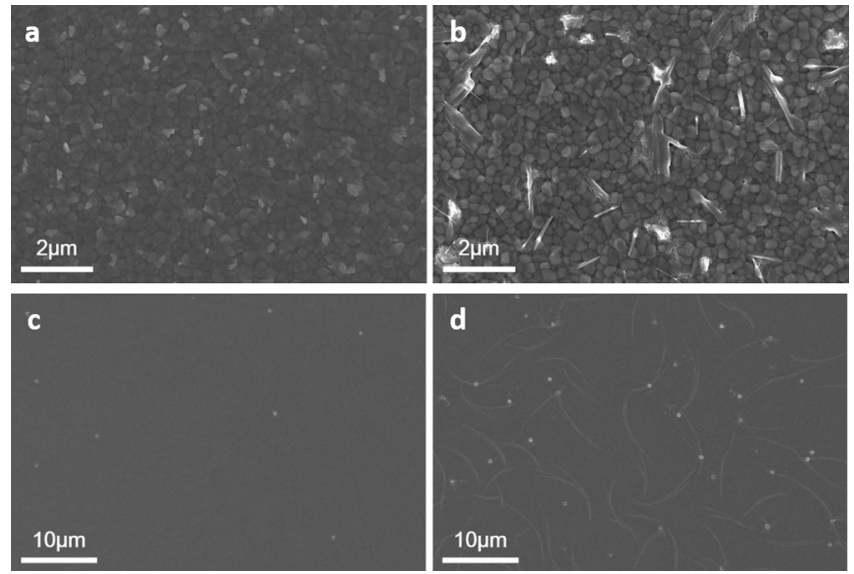

Figure 3. SEM top view of the layers $(a, c)$ without and (b, d) with rGO: (ab) perovskite and (c-d) spiro-OMeTAD. (b, d) Note the presence of aggregates on the surface in the samples with rGO, which can create shunt pathways between $\mathrm{m}-\mathrm{TiO}_{2}$, perovskite/spiro-OMeTAD, and gold.

the contrary, when we added the $\mathrm{rGO}$ in the $\mathrm{m}-\mathrm{TiO}_{2}$ layer, the highest PCEs were obatined. Both the open-circuit voltage $\left(V_{O C}\right)$ and fill factor (FF) were improved, resulting in the best performing device with PCE maximum of $19.54 \%$. We conclude that the addition of $\mathrm{rGO}$ only has a beneficial effect on the PSC performance when mixed with the $\mathrm{m}-\mathrm{TiO}_{2}$ layer. The statistics of the efficiency distribution shown in Figure $\mathrm{S} 5 \mathrm{a}$ and $b$ demonstrate the repeatability of the enhancement achieved by employing $\mathrm{rGO}$ in the $\mathrm{m}-\mathrm{TiO}_{2}$ layer.

To further unveil the effects of the $\mathrm{rGO}$ incorporation in the $\mathrm{m}-\mathrm{TiO}_{2}$ layer, we also fabricated devices without the Li treatment on $\mathrm{TiO}_{2}$ electrode. Li treatment is usually performed for the high-efficiency solar cells, because it has a beneficial role in passivating the surface traps and improving electron injection. ${ }^{[20,25]}$ We compare in Figure $4 a$ the $J-V$ curves with and without $\mathrm{Li}$-treated $\mathrm{TiO}_{2}$ electrodes and/or rGO. Note that without the $\mathrm{Li}$ treatment the performances are overall reduced with PCE values of around $17 \%$, as shown in Table 1. The efficiency statistics of these devices is also depicted in Figure S5c.

We note that the difference from insertion of $\mathrm{rGO}$ in the untreated $\mathrm{m}-\mathrm{TiO}_{2}$ electrode is lower compared with the Li-treated
$\mathrm{m}-\mathrm{TiO}_{2}+\mathrm{rGO}$ devices. Although the device using untreated $\mathrm{m}-\mathrm{TiO}_{2}+\mathrm{rGO}$ shows an increased FF and short-circuit current density $\left(J_{S C}\right)$, suggesting an improved electron-injection pathway, the $V_{\mathrm{OC}}$ is reduced. From our results, it is clear that devices incorporating Li-treated $\mathrm{m}-\mathrm{TiO}_{2}+\mathrm{rGO}$ yield the best performance.

The role of the rGO was further studied by monitoring the photoluminescence $(\mathrm{PL})$ decays of the devices with Li-treated $\mathrm{m}-\mathrm{TiO}_{2}+\mathrm{rGO}$. The presence of $\mathrm{rGO}$ induces a quenching of the $\mathrm{PL}$ signal (see Figure S6). Figure $4 \mathrm{~b}$ shows the PL dynamics at $770 \mathrm{~nm}$ upon excitation at $460 \mathrm{~nm}$. The control sample, containing untreated $\mathrm{m}-\mathrm{TiO}_{2}$ without $\mathrm{rGO}$, shows a long-living decay out of our temporal window reflecting the intrinsic electron-hole recombination dynamic in the perovskite. ${ }^{[26]}$ On the contrary, we observed that the presence of the $\mathrm{GO}$ quenches the PL signal. This might indicate that, among other processes, electron transfer is facilitated in the presence of the rGO. The quenching happens on a time scale of a few tens of ns. Table S1 shows the parameters derived from exponential fitting of the PL decays. On the other side, when both $\mathrm{rGO}$ and $\mathrm{Li}$ TFSI were mixed with the $\mathrm{m}-\mathrm{TiO}_{2}$, an even faster quenching component was observed, resulting in an initial PL decay within $1 \mathrm{~ns}$, which corresponds to the resolution of our system. This can be attributed to more efficient and faster electron injection at the treated interface owing to the synergic positive effects of improving the electron extraction. For the sake of completeness, note that no differences were observed when we probed the PL decay upon exciting selectively the perovskite capping layer (Figure S7), supporting the role of rGO exclusively on the interfacial dynamics.

The overall study presents a thorough analysis of the role of rGO integrated into PSCs, elucidating its main role in improving electron transport when mixed with the $\mathrm{m}-\mathrm{TiO}_{2}$ layer. In the other case, unwanted shunt resistance pathways are generated if the $\mathrm{rGO}$ is incorporated with the perovskite or spiroOMeTAD layers, reducing the overall device performance. In addition, from the synergic effect of the $\mathrm{rGO}$ and $\mathrm{Li}$ treatment in the $\mathrm{m}-\mathrm{TiO}_{2}$ layer, the device yielded a superior PCE of $19.54 \%$, which is ascribed to the beneficial role of $\mathrm{rGO}$ in extracting electrons through the ETM. We believe that our com-
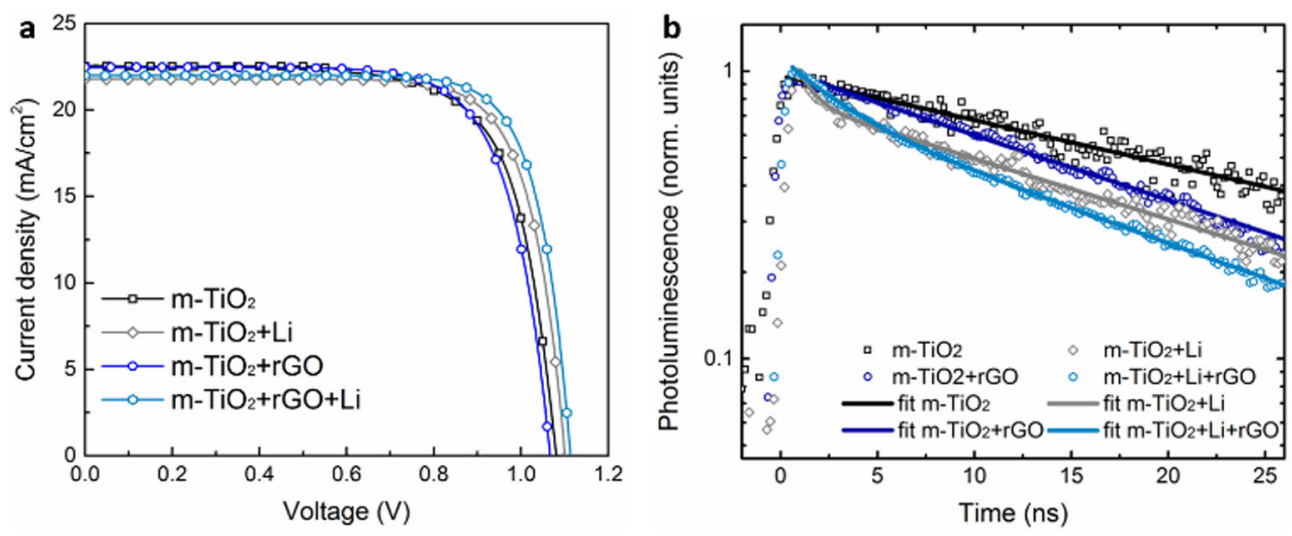

Figure 4. (a) $J-V$ characteristics of the solar cells whose parameters are presented in Table 1. (b) Normalized PL decay measured at 770 nm upon excitation at $460 \mathrm{~nm}$ from the $\mathrm{m}-\mathrm{TiO}_{2}$ side for samples with and without $\mathrm{rGO}$ and/or Li doping in the HTM, as indicated in the legend. Solid lines represent the outcome of the exponential fitting. See Table S1 for fitting parameters. All the samples have been encapsulated to prevent oxygen or moisture degradation. 
bined system of $\mathrm{rGO}$ and $\mathrm{Li}$ treatment may pave the way for further developing and optimizing the electron transport and collection behind high efficient PSCs.

\section{Experimental Section}

\section{Preparation of graphene oxide ${ }^{[27]}$}

Graphene oxide was prepared from graphite powder (Alfa Aesar, $\sim 200$ mesh) according to a modified Hummers' method. In more detail, graphite powder $(0.5 \mathrm{~g})$ was placed into a mixture of sulfuric acid $(40 \mathrm{~mL}, 98 \%)$ and sodium nitrate $(0.375 \mathrm{~g})$. The mixture was then stirred and cooled in an ice bath. While maintaining vigorous stirring, potassium permanganate $(3.0 \mathrm{~g})$ was added in portions over a period of $2 \mathrm{~h}$. The reaction mixture was left for $4 \mathrm{~h}$ to reach room temperature before being heated at $35^{\circ} \mathrm{C}$ for $30 \mathrm{~min}$. It was then poured into a flask containing deionized water $(50 \mathrm{~mL})$ and further heated at $70^{\circ} \mathrm{C}$ for $15 \mathrm{~min}$. The mixture was then decanted into $250 \mathrm{~mL}$ of deionized water and the unreacted $\mathrm{KMnO}_{4}$ was removed by adding $3 \%$ hydrogen peroxide. The reaction mixture was then allowed to settle and decanted. The obtained graphite oxide was purified by repeated centrifugation and redispersed in deionized water until a neutralized $\mathrm{pH}$ was achieved. Finally, the resulting graphene oxide was dried at $60^{\circ} \mathrm{C}$ in a vacuum oven for $48 \mathrm{~h}$ before use.

\section{Preparation of $\mathrm{rGO}^{[28]}$}

The reduction of graphene oxide was performed using a mixture of hydriodic acid (55\%)/acetic acid. In detail, the as-prepared graphene oxide powder $(0.1 \mathrm{~g})$ was sonicated in acetic acid $(37 \mathrm{~mL})$ for $2 \mathrm{~h}$. Hydroiodic acid $(2 \mathrm{~mL})$ was then added and the mixture was stirred at $40^{\circ} \mathrm{C}$ for $40 \mathrm{~h}$. After being isolated by filtration, the product was washed through a three-step procedure using saturated sodium bicarbonate $(3 \times 2.5 \mathrm{~mL})$, distilled water $(3 \times 2.5 \mathrm{~mL})$, and acetone $(2 \times 2.5 \mathrm{~mL})$. Finally, the resulting $\mathrm{rGO}$ was dried at $60^{\circ} \mathrm{C}$ in a vacuum oven overnight.

\section{Device fabrication}

FTO (NSG 10)-coated glass was used as a substrate and was cleaned in $2 \%$ Hellmanex water solution by sonication, and then rinsed, first in water and finally in ethanol and acetone. A holeblocking layer of compact $\mathrm{TiO}_{2}$ was deposited on the cleaned FTO by using spray pyrolysis at $450^{\circ} \mathrm{C}$. The precursor spray solution was prepared by diluting titanium diisopropoxide (30\% in isopropanol, Sigma-Aldrich) in ethanol by the proportions 5:95 by volume. Oxygen was used as a carrier gas. After spraying, the FTO was cooled to room temperature. On top of the compact $\mathrm{TiO}_{2}$ layer, a $\mathrm{m}-\mathrm{TiO}_{2}$ layer was fabricated by first spin-coating $\mathrm{TiO}_{2}$ nanoparticles at $2000 \mathrm{rpm}$ for $10 \mathrm{~s}$. $\mathrm{TiO}_{2}$ paste (Dyesol $30 \mathrm{NR}-\mathrm{D}$ ) was diluted in ethanol at a concentration of $125 \mathrm{mg} \mathrm{mL}^{-1}$ and used for mesoporous layer. Then substrates were sintered at on a hot plate for $30 \mathrm{~min}$ and then slowly cooled down. For Li treatment on the $\mathrm{TiO}_{2}$ layer, the substrates were re-heated to $450^{\circ} \mathrm{C}$ and maintained at this temperature for $30 \mathrm{~min}$ after spin coating a $0.1 \mathrm{M}$ lithium bistrifluoromethanesulfonimidate (Li-TFSI, Sigma-Aldrich) in acetonitrile (Acros) at $3000 \mathrm{rpm}$ for $10 \mathrm{~s}$. After cooling, they were transferred directly into a nitrogen glovebox. A perovskite precursor solution was spin-coated in the glove box. The (FAP$\left.\mathrm{bl}_{3}\right)_{0.85}\left(\mathrm{MAPbBr}_{3}\right)_{0.15}$ precursor solution was composed of FAI $(1 \mathrm{M})$, $\mathrm{Pbl}_{2}$ (1.1 M, Sigma-Aldrich), $\mathrm{MABr}(0.2 \mathrm{M})$, and $\mathrm{PbBr}_{2}$ (0.2 M, Sigma-
Aldrich) in anhydrous DMF/DMSO (Acros) $=4: 1 \mathrm{v} / \mathrm{v}^{[21,22]}$ This composition contains a lead excess as reported previously. The solution was spin-coated at $1000 \mathrm{rpm}$ for $10 \mathrm{~s}$ and continuously at $6000 \mathrm{rpm}$ for $30 \mathrm{~s}$. During the second step, when approximately $15 \mathrm{~s}$ left before finish, $100 \mu \mathrm{L}$ of anhydrous chlorobenzene was added. After spin-coating, the films were annealed on a hotplate at $100^{\circ} \mathrm{C}$ for $90 \mathrm{~min}$. If the perovskite films were cooled to ambient temperature, a $70 \mathrm{~mm}$ solution of spiro-OMeTAD (Merck) dissolved in chlorobenzene (Acros) was spin-coated on top of the films at $4000 \mathrm{rpm}$ for $20 \mathrm{~s}$. Three different additives were added to the spiro-OMeTAD solution: 4-tert-butylpyridine (TBP), Li-TFSI in acetonitrile, and FK209 (Dyesol) in acetonitrile. The molar ratio of spiroOMeTAD/FK209/Li-TFSI/TBP was 1:0.03:0.5:3.3. Lastly, the $70 \mathrm{~nm}$ thick Au counter electrode was deposited by thermal evaporation. In this experiment, a specified concentration of rGO added to the spiro-OMeTAD or perovskite solutions was limited to $0.055 \mathrm{mg} \mathrm{mL}^{-1}$ and $0.01 \mu \mathrm{g} \mathrm{mL}^{-1}$, respectively, because $\mathrm{rGO}$ has limited solubility in each solvent. In a mixed solvent of DMF/DMSO (perovskite solution) and chlorobenzene (spiro-OMeTAD solution), these concentrations showed no precipitate after sonication for $2 \mathrm{~h}$. In the case of $\mathrm{TiO}_{2}$, we chose the concentration when a maximum efficiency was obtained from an incorporation of $\mathrm{rGO}$ in the $\mathrm{m}-\mathrm{TiO}_{2}$ layer.

\section{Solar cell characterization}

The solar cells were characterized using a $450 \mathrm{~W}$ xenon light source (Oriel) equipped with a Keithley 2400 source meter. The light intensity was measured by a certified reference $\mathrm{Si}$ cell equipped with an IR-cutoff filter, KG5 (Newport), and it was adjusted to $1000 \mathrm{Wm}^{-2}$ during each measurement. A black metal mask of $0.16 \mathrm{~cm}^{2}$ was used to fix the active area of the solar cells and a scan rate is $2.5 \mathrm{mV} \mathrm{s}^{-1}$ on forward and backward scans. A ZEISS Merlin high-resolution scanning electron microscope (HR-SEM) was performed for the morphology of the device cross-section and surface of films. X-ray powder diffraction (XRD) was recorded on an D8 advance (Brucker) equipped with a ceramic tube ( $\mathrm{Cu}$ anode, $\lambda=1.54060 \AA$ ) in an angle range of $2 \theta=10-70^{\circ}$.

\section{PL experiment}

Steady state PL spectra were recorded using a spectrophotometer (Gilden Photonics) equipped with a cw Xenon lamp utilized for excitation. To detect the time-resolved PL trace, a pulsed source at $460 \mathrm{~nm}$ (Ps diode lasers BDS-SM, pulse with $<100 \mathrm{ps,} \mathrm{from} \mathrm{Photon-}$ ic Solutions, approx. $1 \mathrm{~mW}$ power, $20 \mathrm{MHz}$ repetition rate, approx. 500 um spot radius) was used as excitation and the signal is recorded at $770 \mathrm{~nm}$ by the time-correlated single-photon counting detection technique with a time resolution of $1 \mathrm{~ns}$. Excitation density of $\sim 10 \mathrm{~nJ} \mathrm{~cm}^{-2}$. All the samples have been encapsulated to prevent degradation or any oxygen/moisture-induced effects. A monoexponential and bi-exponential fitting are used to analyze the background-corrected PL decay signal.

\section{Acknowledgements}

The authors acknowledge SNSF NRP 70 project; number: 407040_154056. G.G. acknowledges support from the 'EPFL Fellows' fellowship programme co-funded by Marie SkłodowskaCurie, Horizon 2020 Grant agreement no. 665667. D.K and E.K acknowledge funding from the European Union's Horizon 2020 re- 
search and innovation programme under grant agreement No. 696656 - GrapheneCore1.

Keywords: active interface $\cdot$ charge transfer dynamics $\cdot$ hybrid perovskite $\cdot$ perovskite solar cells $\cdot$ reduced graphene oxide

[1] K. S. Novoselov, A. K. Geim, S. V. Morozov, D. Jiang, Y. Zhang, S. V. Dubonos, I. V. Grigorieva, A. A. Firsov, Science 2004, 306, 666.

[2] H.-X. Wang, Q. Wang, K.-G. Zhou, H.-L. Zhang, Small 2013, 9, 1266.

[3] T.-F. Yeh, C.-Y. Teng, L.-C. Chen, S.-J. Chen, H. Teng, J. Mater. Chem. A 2016, 4, 2014.

[4] Z. Chen, W. Ren, L. Gao, B. Liu, S. Pei, H.-M. Cheng, Nat. Mater. 2011, 10, 424.

[5] S. Park, R. S. Ruoff, Nat. Nanotechnol. 2009, 4, 217.

[6] Z. Yin, J. Zhu, Q. He, X. Cao, C. Tan, H. Chen, Q. Yan, H. Zhang, Adv. Energy Mater. 2014, 4, 1300574.

[7] N. Balis, E. Stratakis, E. Kymakis, Mater. Today 2016, DOI:10.1016/ j.mattod.2016.03.018.

[8] N. R. E. L. (NREL), Research Cell Efficiency Records.

[9] J. T.-W. Wang, J. M. Ball, E. M. Barea, A. Abate, J. A. Alexander-Webber, J. Huang, M. Saliba, I. Mora-Sero, J. Bisquert, H. J. Snaith, R. J. Nicholas, Nano Lett. 2014, 14, 724.

[10] W. Li, H. Dong, X. Guo, N. Li, J. Li, G. Niu, L. Wang, J. Mater. Chem. A 2014, 2, 20105

[11] G. S. Han, Y. H. Song, Y. U. Jin, J.-W. Lee, N.-G. Park, B. K. Kang, J.-K. Lee, I. S. Cho, D. H. Yoon, H. S. Jung, ACS Appl. Mater. Interfaces 2015, 7, 23521.

[12] M. Batmunkh, C. J. Shearer, M. J. Biggs, J. G. Shapter, J. Mater. Chem. A 2016, 4, 2605.

[13] J.-S. Yeo, R. Kang, S. Lee, Y.-J. Jeon, N. Myoung, C.-L. Lee, D.-Y. Kim, J.-M. Yun, Y.-H. Seo, S.-S. Kim, S.-I. Na, Nano Energy 2015, 12, 96.

[14] E. Stratakis, K. Savva, D. Konios, C. Petridis, E. Kymakis, Nanoscale 2014, 6,6925
[15] D. Konios, G. Kakavelakis, C. Petridis, K. Savva, E. Stratakis, E. Kymakis, J. Mater. Chem. A 2016, 4, 1612.

[16] G. Kakavelakis, D. Konios, E. Stratakis, E. Kymakis, Chem. Mater. 2014, 26, 5988.

[17] A. Agresti, S. Pescetelli, L. Cinà, D. Konios, G. Kakavelakis, E. Kymakis, A. D. Carlo, Adv. Funct. Mater. 2016, 26, 2686

[18] K. Aitola, K. Sveinbjornsson, J. P. Correa-Baena, A. Kaskela, A. Abate, Y. Tian, E. M. J. Johansson, M. Grätzel, E. I. Kauppinen, A. Hagfeldt, G. Boschloo, Energy Environ. Sci. 2016, 9, 461.

[19] W. S. Yang, J. H. Noh, N. J. Jeon, Y. C. Kim, S. Ryu, J. Seo, S. I. Seok, Science 2015, 348, 1234.

[20] F. Giordano, A. Abate, J. P. Correa Baena, M. Saliba, T. Matsui, S. H. Im, S. M. Zakeeruddin, M. K. Nazeeruddin, A. Hagfeldt, M. Grätzel, Nat. Commun. 2016, 7, 10379.

[21] J. P. Correa Baena, L. Steier, W. Tress, M. Saliba, S. Neutzner, T. Matsui, F. Giordano, T. J. Jacobsson, A. R. Srimath Kandada, S. M. Zakeeruddin, A. Petrozza, A. Abate, M. K. Nazeeruddin, M. Grätzel, A. Hagfeldt, Energy Environ. Sci. 2015, 8, 2928-2934.

[22] J. Seo, N. J. Jeon, W. S. Yang, H.-W. Shin, T. K. Ahn, J. Lee, J. H. Noh, S. I. Seok, Adv. Energy Mater. 2015, 5, 1501320.

[23] M. Acik, S. B. Darling, J. Mater. Chem. A 2016, 4, 6185-6235.

[24] M. Hadadian, J.-P. Correa-Baena, E. K. Goharshadi, A. Ummadisingu, J.-Y. Seo, J. Luo, S. Gholipour, S. M. Zakeeruddin, M. Saliba, A. Abate, M. Grätzel, A. Hagfeldt, Advanced Materials 2016, DOI: 10.1002/ adma.201602785.

[25] J. H. Heo, M. S. You, M. H. Chang, W. Yin, T. K. Ahn, S.-J. Lee, S.-J. Sung, D. H. Kim, S. H. Im, Nano Energy 2015, 15, 530

[26] S. D. Stranks, G. E. Eperon, G. Grancini, C. Menelaou, M. J. P. Alcocer, T. Leijtens, L. M. Herz, A. Petrozza, H. J. Snaith, Science 2013, 342, 341.

[27] D. Li, M. B. Muller, S. Gilje, R. B. Kaner, G. G. Wallace, Nat. Nanotechnol. 2008, 3, 101.

[28] I. K. Moon, J. Lee, R. S. Ruoff, H. Lee, Nat. Commun. 2010, 1, 73.

Received: August 5, 2016

Published online on II, 0000 


\section{COMMUNICATIONS}

K. T. Cho, G. Grancini, Y. Lee, D. Konios,

S. Paek, E. Kymakis, M. K. Nazeeruddin*

Beneficial Role of Reduced Graphene Oxide for Electron Extraction in Highly Efficient Perovskite Solar Cells

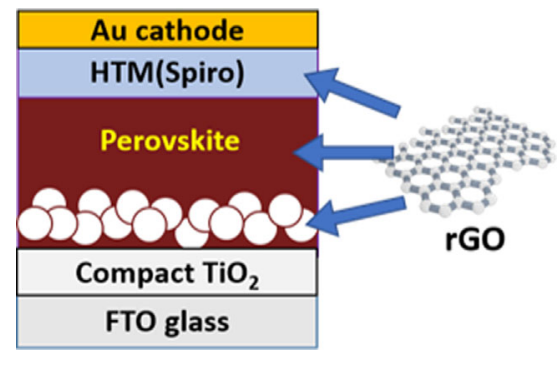

rGO for efficiency! The effect of incorporating reduced graphene oxide ( $\mathrm{rGO}$ ) within the electron-transport, active, and hole-transport layers of a perovskite solar cell is investigated. Incorporation of $\mathrm{rGO}$ into the mesoporous $\mathrm{TiO}_{2}$ matrix results in highly efficient solar cells with power conversion efficiency of up to $19.54 \%$. 